\title{
An Investigation on the Effects of Different Time Resolutions in the Design and Simulation of BHE Fields
}

\section{Marco Fossa}

\begin{abstract}
The correct design of a field of Borehole Heat Exchangers (BHE) requires the knowledge of ground thermal properties, heat pump performance and building heating and cooling demand. The sequence of heat pulses from (to) the ground by the heat pump can be described according to different time steps, from hours to months and even years. The monthly time step approach is often the preferred design choice which involves recursive calculations (temporal superposition techniques) and the availability of precalculated temperature response factors (or g-functions) for given BHE field geometries. Such a complex computing task is usually performed thanks to commercial codes in order to fulfil a carrier fluid temperature at the end of a given time horizon, typically 10 or 25 years. In this paper the monthly design approach (EED code and TecGeo proprietary code) is compared with the three thermal pulse approach (modified ASHRAE Method Tp8) and it is demonstrated that for a representative series of case studies the three pulse calculation, easy to be performed at engineering level, is able to provide the correct BHE field overall length with $8 \%$ accuracy with respect to the reference monthly calculations.
\end{abstract}

\section{INTRODUCTION}

In ground coupled heat pump (GCHP) applications, the advantages of borehole heat exchangers (BHE) with respect to their shallow counterparts (trench and horizontal ground heat exchangers) are various, including the favourable temperatures of the soil when increasing the distance from the surface, a great freedom in choosing the best disposition of the heat exchangers in the building site, well assessed techniques for drilling the BHE, reliable models for modelling its thermal behaviour and interactions with the surrounding ground for overall system performance simulations. Concerning the theoretical part of the BHE field design process, the best approach for defining the final BHE field geometry for target system performance (in terms of given COP or overall seasonal performance factor parameters) is to employ precalculated temperature response factors (TRF) for performing ground response simulations where the heat transfer rate is variable in time.

The ground volume is very often modelled according to the thermal conduction laws. Starting from the early contributions by Carslaw and Jaeger (1947) and Ingersoll et al. (1954) that provide the ground theoretical response to simple heat sources (Infinite line and cylindrical sources, ILS and ICS, respectively), new models and related TRF have been developed in order to cope with the geometrical complexity of the real BHE fields (Eskilson 1987, Spitler and Yavuzturk 1999, Lamarche and Beauchamp 2007, Claesson and Javed 2011, Cimmino et al. 2013).

The variability of the heat loads at ground level is the consequence of the building heat demand which is

Marco Fossa (marco.fossa@unige.it) is professor of Solar and Geothermal Energy and Antonella Priarone is research professor, both at the University of Genova, Italy. Dav ide Rolando is research engineer at KTH Stockholm, Sweden. 
intrinsically transient in time due to the heat pump daily and weekly duty cycles and weather effects. This variability of the heat transfer rate from (to) the ground can be tackled by applying suitable temporal superposition techniques (e.g. Spitler and Yavuzturk 1999). As it is well known the time resolution at which the heat load variation can be taken into account varies typically from hours to months, being the former approach the most reliable according to designers and researcher in this field. Since hourly simulations are time consuming from a computational point of view and also because often the input hourly data in terms (building thermal needs) are not available a common approach is to focus the analysis on a monthly time step, eventually including in the process of temporal superposition single short (hourly scale) contributions. This criterion is the one adopted in the well known calculation tools GLHEPRO (Spitler 2000) and EED (Hellstrom and Sanner, 1994). On the other hand since about 20 years a simplified model has been proposed which is based on the description of the building/ground thermal interactions in terms of only 3 contributions over 10 years (triple step model, Kavanaugh and Rafferty, 1997, Bernier 2006, Ashrae 2015). This method, known as the Ashrae method, has the fundamental advantage that it can be implemented in simple spreasheets and does not need dedicated softwares. Recently the present Authors have developed further schemes (the $\mathrm{T}_{\mathrm{p} 8}$ method, Fossa and Rolando 2016, Fossa 2016) for applying the Ashrae Method to BHE field design that according to them are either more precise or faster than previous literature methods based on the evaluation of the Temperature Penalty parameter.

In this paper the Authors present a comprehensive series of comparisons related to monthly (sequence of 121 heat loads) vs triple step simulations devoted to the estimation of the required overall BHE field length. The overall time horizon is 10 years, taking into consideration different monthly profiles and a variety of BHE field geometries (e.g. square, in-line configurations). The monthly calculations are performed with either the EED code or the proprietary code TecGeo (Dalla Pietà and Fossa, 2006).

The aim of the paper is to assess the reliability of the three step approach (in terms of the $T_{p}$ method) with respect to the monthly approach when the BHE length is estimated based on a constraint related to the minimum temperature of the carrier fluid during the analisys period. A short discussion is finally provided about the influence of different TRFs (i.e. based on heat rate or temperature boundary conditions, see Priarone and Fossa 2016) on the final results of the design process and about the possibility to extend the $\mathrm{T}_{\mathrm{p} 8}$ method to longer time horizons ( 25 years).

\section{THE MODIFIED ASHRAE METHOD ACCORDING TO THE TP8 MODEL}

The $\mathrm{T}_{\mathrm{p} 8}$ method is a recent model developed by the Authors which exploits the linear properties of the conduction equation for obtaining reliable formulas able to describe the ground thermal response to BHE systems in a great variety of BHE geometries.

The model, its accuracy and the comparison with literature similar methods are described in details in three papers by the Authors (Fossa and Rolando 2015, Fossa and Rolando 2016, Fossa 2016). Here in the following the main calculation steps of the $\mathrm{T}_{\mathrm{p} 8}$ approach are briefly presented. 


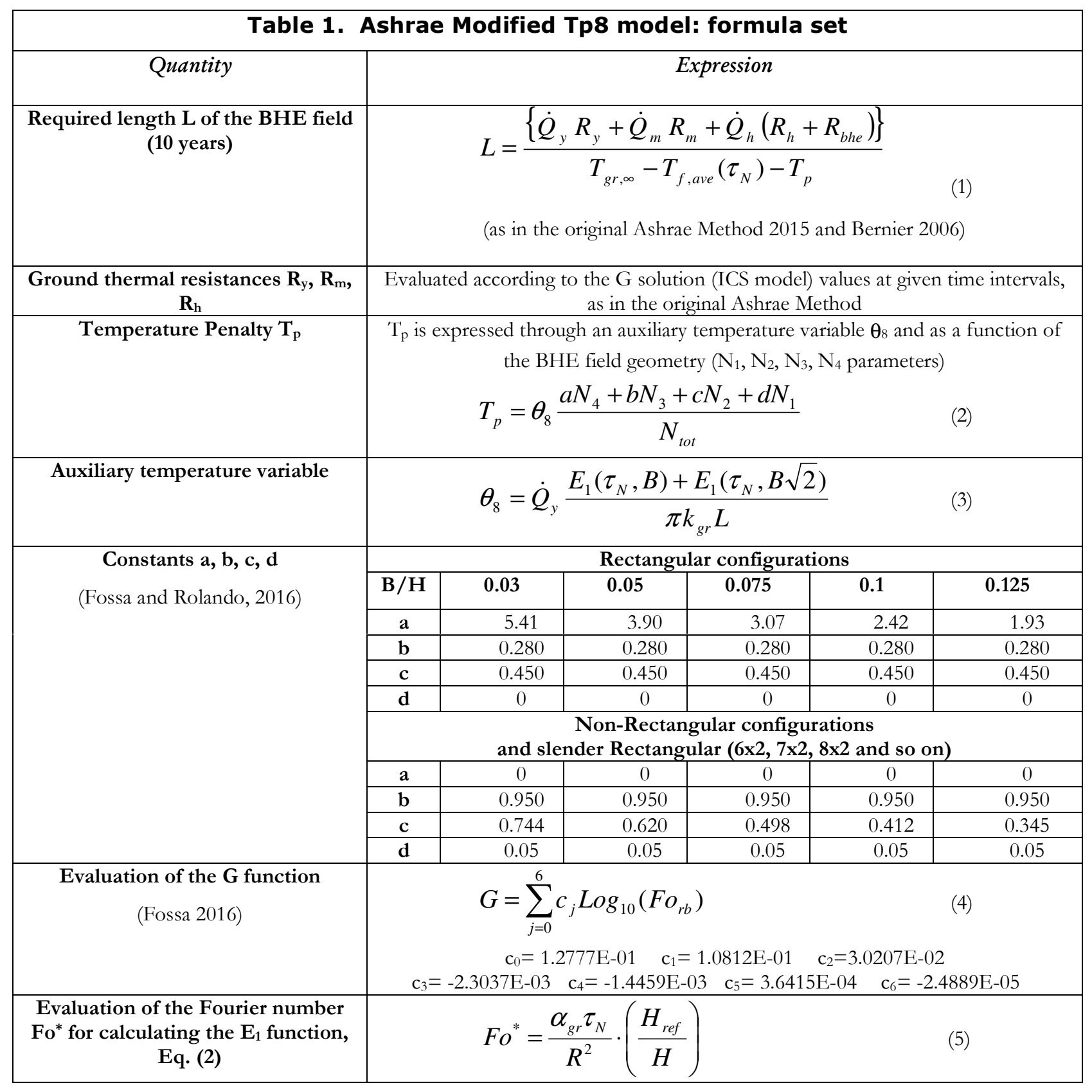

As it well known the Ashrae method allows the calculation of the BHE field overall required length $\mathrm{L}$ in terms of the ground properties (being $k_{\mathrm{gr}}, \alpha_{\mathrm{gr}}$ and $\mathrm{T}_{\mathrm{gr}, \infty}$ its thermal conductivity, diffusivity, and undisturbed temperature, respectively), the building heat transfer rates $\dot{Q}$ to (from) the ground in three time steps (10 years, 1 month, 6 hours, subscripts $y, m, h$ respectively), the borehole effective thermal resistance $\mathrm{R}_{\mathrm{bhe}}$ and the target carried fluid temperature $\mathrm{T}_{\mathrm{f}, \mathrm{ave}}$ at the end of the analysis period ( $\tau_{\mathrm{N}}$ equal to 10 years plus 1 month plus 6 hours). The Ashrae method is based on the calculation of the ground thermal resistances $R_{y}, R_{m}$ and $R_{h}$ starting from the $G$ solution (also known as the ICS solution, Ingersoll et al. 1954) and introduces a correction term (the Temperature Penalty $T_{p}$ ) that represents the 
necessary correction to the simple $\mathrm{G}$ solution when it is employed for describing complex borefield geometries in the late period $\tau_{\mathrm{N}}$ (Fossa 2016).

The complete set of formulas for calculating the required length is given in Table 1.

Further symbol meanings are provided: $\mathrm{E}_{1}$ is the exponential integral (Abramovitz and Stegun, 1964), B is the BHE interdistance, $r_{b}$ is the BHE radius, $H$ is the actual BHE depth and $H_{\text {ref }}$ is a reference depth set equal to $100 \mathrm{~m}$, $\mathrm{N}_{4}, \mathrm{~N}_{3}, \mathrm{~N}_{2}$ and $\mathrm{N}_{1}$ are the number of boreholes (in the BHE field) surrounded by only 4 other ones, only 3 other ones, and so on, respectively.

\section{THE PROCEDURE FOR COMPARING THE DESIGN RESULTS IN TERMS OF DIFFERENT TIME RESOLUTIONS}

Temporal superposition is a well known technique for exploiting base solutions of the transient conduction problem for solving GCHP design tasks when the ground/BHE system is subjected to non constant heat load profiles. Even if hourly load simulations are considered the best way to simulate the borefield response and study the GCHP plant performance very often such an analysis is performed based on the knowledge of the building heating and cooling monthly loads. Such thermal loads are usually easily accessible through steady state and even transient simulations of the building (and its thermal plant) interactions with the external environment. When the monthly load approach is applied to the BHE field design problem an additional peak load is usually included in the superposition scheme as discussed in recent studies by the Oklahoma State University research group (e.g. Cullin and Spitler, 2015).

The resulting algorithm is the one embedded in commercial codes like EED or GHLEPRO and in the proprietary code TecGeo developed at the University of Genova Italy:

$$
\begin{aligned}
& T_{f, a v e}\left(\tau_{N}\right)=T_{g r, \infty}+\dot{Q}_{\text {peak }}^{\prime} R_{\text {bhe }}+\frac{1}{2 \pi k_{g r}} \sum_{i=1}^{N}\left(\dot{Q}_{i}^{\prime}-\dot{Q}_{i-1}^{\prime}\right) g\left(F o\left(\tau_{N}-\tau_{i}\right)\right) \\
& +\frac{1}{2 \pi k_{g r}}\left(\dot{Q}_{\text {peak }}^{\prime}-\dot{Q}_{N}^{\prime}\right) g_{\text {peak }}\left(F o\left(\tau_{\text {peak }}\right)\right)
\end{aligned}
$$

where the $\dot{Q}_{i}^{\prime}$ are the monthly average heat rates (per unit length) to the ground and $\mathrm{g}$ is the $\mathrm{g}$-function of that BHE field, i.e. the TRF pertaining that borefield assembly in terms of depth $\mathrm{H}$, spacing $\mathrm{B}$, radius $\mathrm{r}_{\mathrm{b}}$ and disposition (e.g. rectangular, in line, and so on). In the above expression $\dot{Q}_{\text {peak }}^{\prime}$ is the peak load in the worst operating conditions, $\tau_{\text {peak }}$ its duration and $g_{\text {peak }}$ the TRF employed for describing the ground response to this short thermal pulse.

The related heat rates $\dot{Q}_{y}$ and $\dot{Q}_{m}$ of the Ashrae method can be calculated from the 12 monthly values $\dot{Q}_{i}^{\prime}$ as the average along the year and as the worst month condition, respectively. The peak load $\dot{Q}_{h}$ is just the corresponding quantity $\dot{Q}_{\text {peak }}^{\prime}$ multiplied by the BHE depth $\mathrm{H}$.

In this paper two design approaches are compared related to a time horizon of 10 years.

In the reference procedure 121 monthly heat loads are taken into account and they represent 12 monthly loads (from January to December) that replicates for 10 years. The 121st term is representative of the January contribution of the $11^{\text {th }}$ year, in order to cope with the $\tau_{\mathrm{N}}$ horizon of the Ashrae approach.

The second approach is the $\mathrm{T}_{\mathrm{p} 8}$ Ashrae method (Table 1 equation set) which takes into account the average term $\dot{Q}_{y}$ and the (worst) month contribution $\dot{Q}_{m}$ which corresponds in the present analysis to the January monthly heat load.. Both procedures include the same peak load. Since the Ashrae method cannot account for multiple peak loads, in monthly simulations a single peak load is superposed at the above worst monthly contribution. On the other hand, while searching for the minimum fluid temperature during the years, the selection of a single peak load applied 


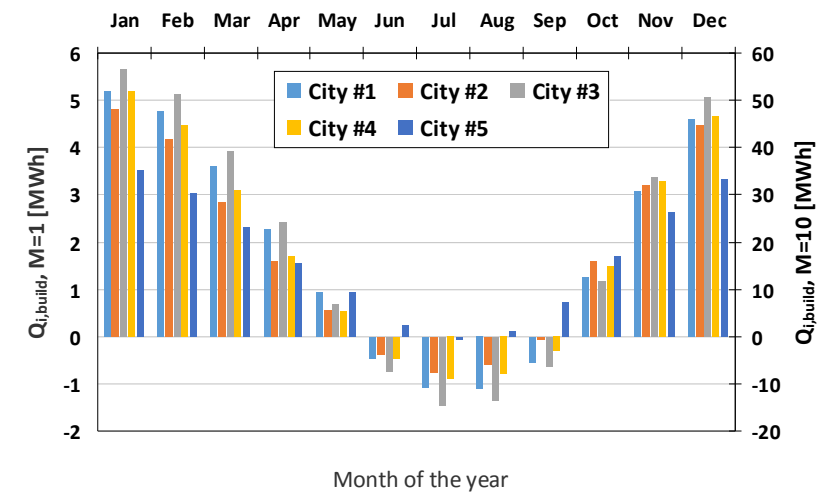

(a)

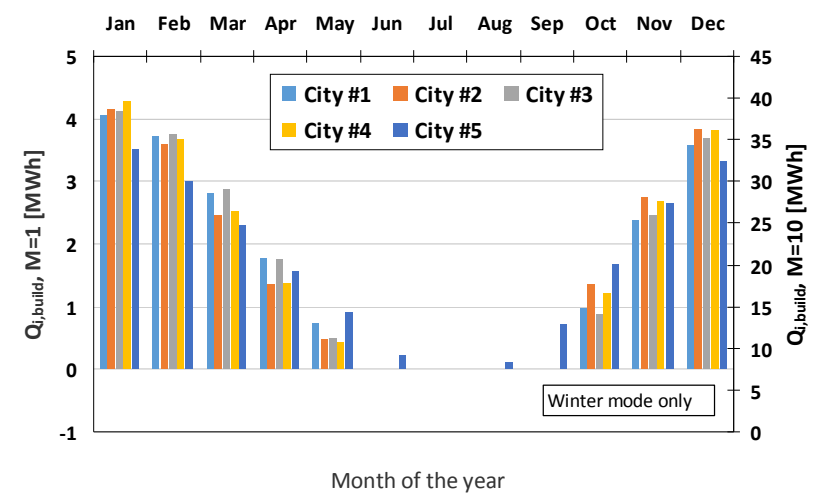

(b)

Figures 1 Monthly load profiles taken as input values for BHE field design. Condition (b) refers to heating operations only

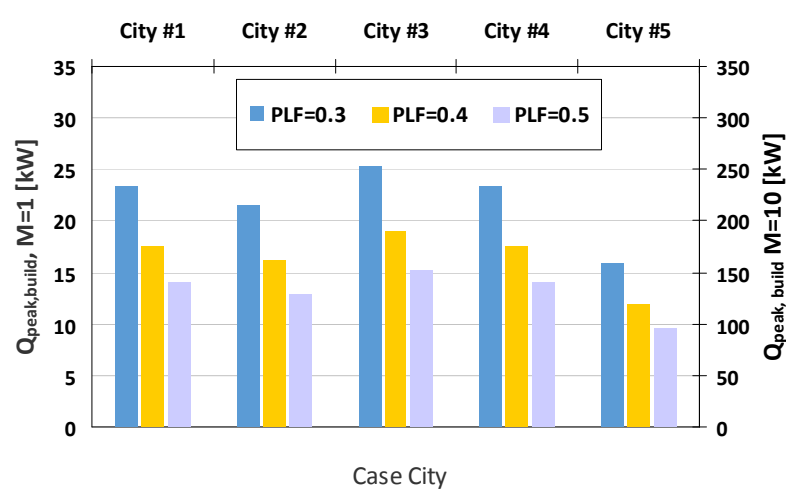

(a)

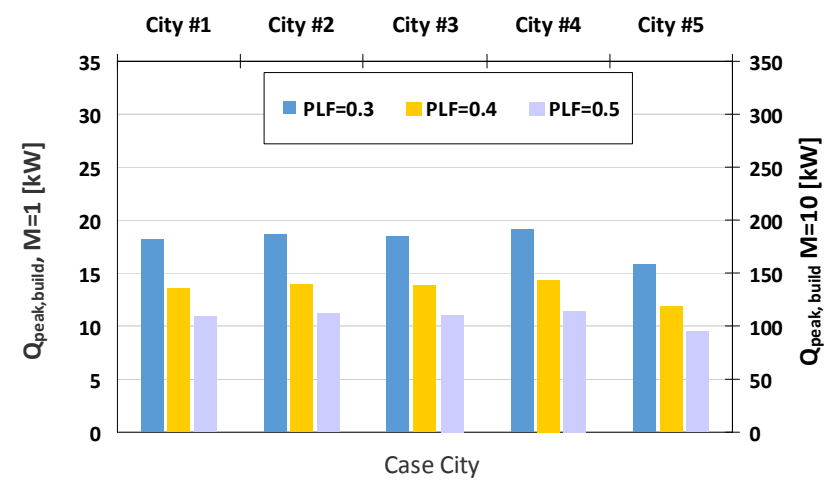

(b)

Figure 2 Peak loads taken as input values for BHE field design.

Three different conditions have been considered as the effect of different partial load factors (PLF) Condition (b) refers to heating operations only

to the "worst" month is typically enough and to take into consideration additional peak loads it is not necessary.

A series of test cases have been taken into account in terms of monthly heat load and peak load distributions to cope with the typical heat demand profiles of Italian sites. Heat monthly profiles has been calculated based on local weather conditions while the peak load has been set equal to the January average heat rate divided by a partial load factor (PLF) parameter which has been arbitrary chosen in a range of typical values.

Figure $1 \mathrm{a}$ and $1 \mathrm{~b}$ show the monthly load distributions (energy per month required by the building) for the 5 case cities taken into consideration and they refer to 2 different building sizes, characterized by a heat demand multiplier $\mathrm{M}$ equal to 1 and 10, respectively. Figure 1a is a general case where either the heating and cooling loads are taken into consideration while Figure $1 \mathrm{~b}$ refer to a condition where the GCHP duty is only heating, say to work only in winter mode. This last condition is addressed to emphasize the role of the correct evaluation of the $T_{\mathrm{p}}$ term (Fossa 2016), which is proportional to $\dot{Q}_{y}$ and hence gains importance when the building yearly load profile is markedly unbalanced (winter only or summer only operating modes).

Figures $2 \mathrm{a}$ and $2 \mathrm{~b}$ show the distribution of the peak loads (heat rate required by the building, heating operation only is case b) for the 5 case cities and considering a PLF parameter assuming the values 0.3, 0.4 and 0.5. 


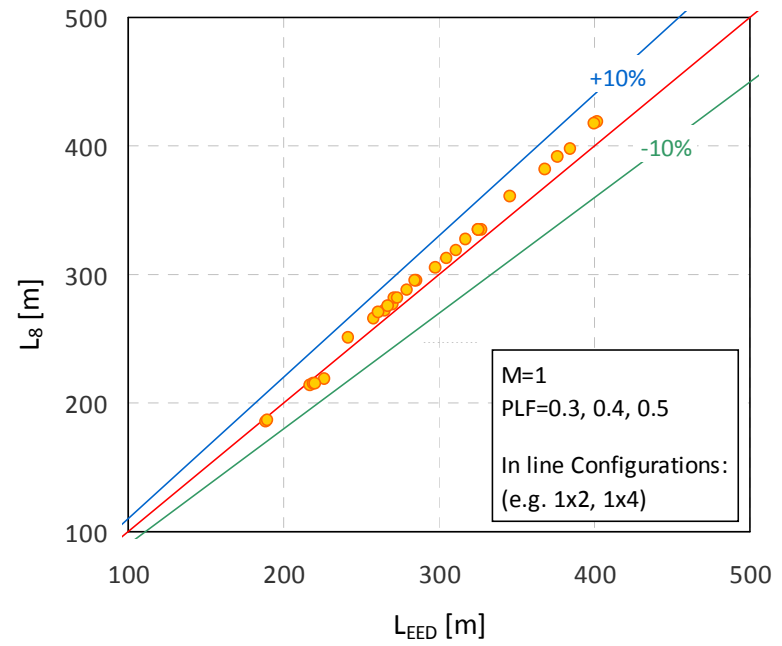

(a)

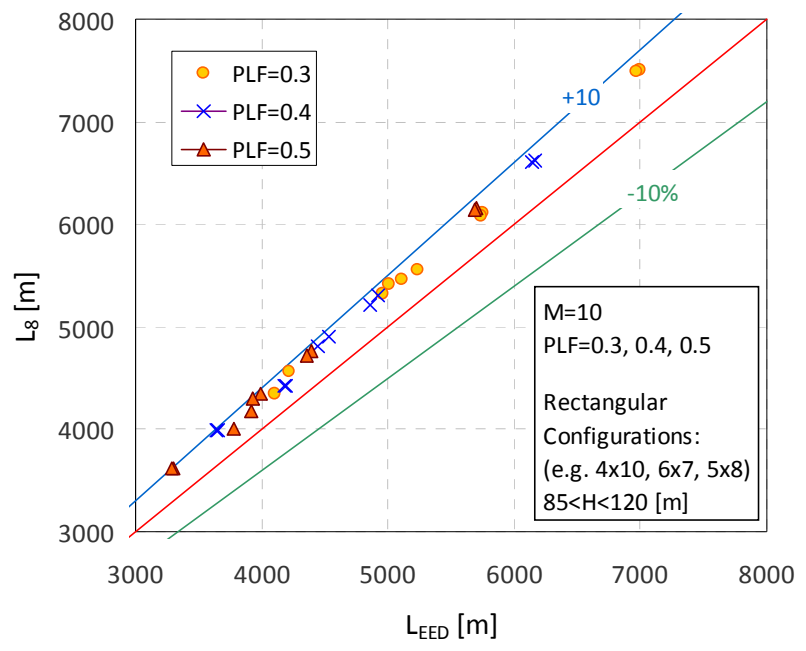

(b)

Figures 3 Calculated overall BHE length $\mathrm{L}$ with the reference method (EED) and the Ashrae/ $\mathrm{T}_{\mathrm{p} 8}$ one. $M=1(a)$ and $M=10(b)$

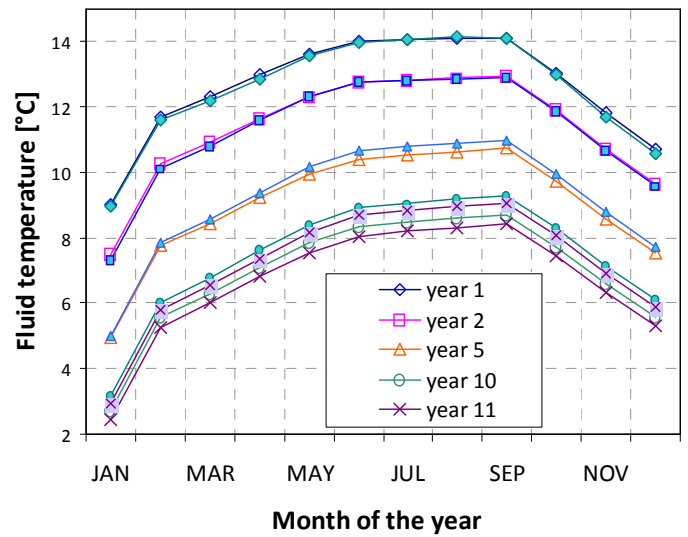

Figures 4 Monthly fluid temperature along the years as calculated with different monthly algorithms. City \#2, PLF=0.4, M=10, winter only loads.

Filled symbols: EED predictions; open symbols: TecGeo predictions

In spite of the fact that the selected input data set for the present design calculations is necessarly arbitrary it can be stated that it is a reasonably comprehensive of many working conditions encountered by GCHP plants in Europe. Further data input are the seasonal performance factor (SPF) which has been set to 4 , $\mathrm{R}_{\mathrm{bhe}}$ set to $0.10 \mathrm{mK} / \mathrm{W}, \mathrm{k}_{\mathrm{gr}}$ set to $2.5 \mathrm{mK} / \mathrm{W}, \alpha_{\mathrm{gr}}$ set to $11 \mathrm{e}-7 \mathrm{~m}^{2} / \mathrm{s}$ and the undisturbed local ground temperature of each case city $\left(\mathrm{T}_{\mathrm{gr}, \infty}\right.$ range: 10 to $\left.16^{\circ} \mathrm{C}\right)$.

The calculations have been performed for attaining a minimum carrier fluid temperature of $3^{\circ} \mathrm{C}$ when the $\mathrm{BHE}$ field is characterized by interdistances B equal to 5 meters. The BHE field geometry has been selected among the rectangular and in-line configurations (e.g 2x1, 3x2, 4x10, 6x7) in order to fulfill the carrier fluid constraint with $\mathrm{BHE}$ depths not exceeding the range 85 to $120 \mathrm{~m}$. 


\section{RESULTS}

Simulations of the fluid temperature evolution in time have been performed with the EED code while imposing the minimum allowed fluid temperature $\left(3^{\circ} \mathrm{C}\right)$ for the given BHE field configuration. The same constraint have been applied to the $T_{p 8}$ algorithm where the constants a, b, c, d and the BHE types $\mathrm{N}_{1}, \mathrm{~N}_{2}, \mathrm{~N}_{3}, \mathrm{~N}_{4}$ have been calculated as a function of the BHE field configuration, the same of the corresponding EED case. With both procedures the overall BHE lengths (and hence the corresponding BHE depths) have been evaluated.

The peak load duration has been set equal to 6 hours, as suggested in the original Ashrae method.

Figure $3 \mathrm{a}$ shows the final overall BHE lenghth as calculated with both the EED code and the modified Ashrae method for the 5 case cities, at different PLF numbers (e.g. at different peak loads for given base load set) when the base load multiplier $\mathrm{M}$ is equal to 1 (monthy load input values: left y-axis of figures $1 \mathrm{a}$ and $1 \mathrm{~b}$ ). The resulting BHE configurations resulted $2 \times 1,3 \times 1$ and $4 \times 1$ for overall lengths not exceeding $500 \mathrm{~m}$. It can be noticed that the monthly design procedure and the three pulse one give practically the same results, with minor discrepancies in the $3 \%$ range. This error is related to the intrinsic error in $\mathrm{T}_{\mathrm{p} 8}$ method for small $\mathrm{BHE}$ fields as a consequence of its best fit constants.

Figure $3 \mathrm{~b}$ is the $\mathrm{M}=10$ version of the previous one: the building heat loads are greater and the resulting BHE fields are larger (up to $7 \times 10$ BHEs). Here the agreement among the reference EED calculation and the Ashrae/ $\mathrm{T}_{\mathrm{p} 8}$ one is still good but major differences arise, of the order of $8 \%$ (in the direction of oversizing the BHE system).

The above discrepancies could be ascribed to the different TRFs employed in EED with respect to those employed during the optimum search of $\mathrm{T}_{\mathrm{p} 8}$ constants (Table 1). As deeply discussed in Fossa and Rolando 2015 and Fossa and Priarone 2016, TRFs (g-functions) can be calculated according to different boundary conditions (i.e. at imposed heat rate, as in TecGeo and $\mathrm{T}_{\mathrm{p} 8}$, or temperature, as in EED) but in the Fo range pertaining to 10 year horizons they should not differ meaningfully.

Figure 4 finally shows the comparison between the time evolution of the carrier fluid temperature for the city \#2, M=10, PLF $=0.4$ as calculated by EED and by the proprietary code TecGeo. The two codes should implement the same overall algorithm while employing different g-function databases. In particular TecGeo works with the same $\mathrm{g}$-functions employed for best fit optimization of $\mathrm{T}_{\mathrm{p} 8}$ method constants. The BHE configuration is this case is $6 \times 7, \mathrm{~B}$ is equal to $5 \mathrm{~m}$ and $\mathrm{H}=107 \mathrm{~m}$. As can be observed the temperature profiles are in close agreement and the maximum fluid temperature diffence is about $0.6^{\circ} \mathrm{C}$ at January of the $11^{\text {th }}$ year. The exact agreement in terms of minimum fliuid temperature it would be obtained by setting $\mathrm{H}_{\mathrm{EED}}=103 \mathrm{~m}$. On the other hand when TecGeo is employed for the same case for calculating the required length, the comparison with the $\mathrm{T}_{\mathrm{p} 8}$ prediction reveals a difference of less $3 \%\left(\mathrm{~L}_{\mathrm{TG}}=107 \mathrm{~m}, \mathrm{~L}_{8}=110 \mathrm{~m}\right)$. It is interesting to notice that for the same input data the original Ashrae method (Kavanaugh and Rafferty, 1997) would provide an overall BHE length of only $82 \mathrm{~m}$. .

These evidences deserve further investigation and maybe a critical review of EED database of TRF functions.

Finally it is worth stressing that a series of simulations have been carried at different $\tau_{\text {peak }}$ values (from 3 to 12 hours) that provided results still in agreement among them (again 8\% differences between EED and $T_{p 8}$ predictions), thus demonstrating once again the reliability of the modified Ashrae method.

\section{CONCLUSIONS}

A series of case tests related to the design of BHE fields have been considered in order to compare the results obtained with a monthly heat load approach with those provided by a modified version of the Ashrae method (the $\mathrm{T}_{\mathrm{p} 8}$ method). The simulations have been performed with respect to a 10 year scenario (121 months) and considering various BHE field configurations, from small in-line geometries $(1 \mathrm{x} 2$ to $1 \mathrm{x} 4)$ to large rectangular dispositions (up to $7 \times 10)$. The overall BHE length ranged from few hundreds meters to 7 thousands.

The paper demonstrates that the modified Ashrae method is able to provide similar results (differences within $8 \%$ ) with respect to the reference calculation procedure (EED code) when the design target is the overall BHE length for given minimum allowed fluid temperature. 
The differences in the predicted lengths can be partially ascribed to the different sets of $g$-functions employed by the reference code and the present procedure: further investigations will be devoted to clarify these aspects.

Current work on the $\mathrm{T}_{\mathrm{p} 8}$ method is finally addressed in the direction of extending its applicability to a 25 year horizon through model tuning in terms of constants and superposition scheme.

\section{ACKNOWLEDGMENTS}

The Authors acknowledge Dr. Silvia Trevisan for the valuable calculations she performed during the development of her Thesis at the University of Genova.

\section{NOMENCLATURE}

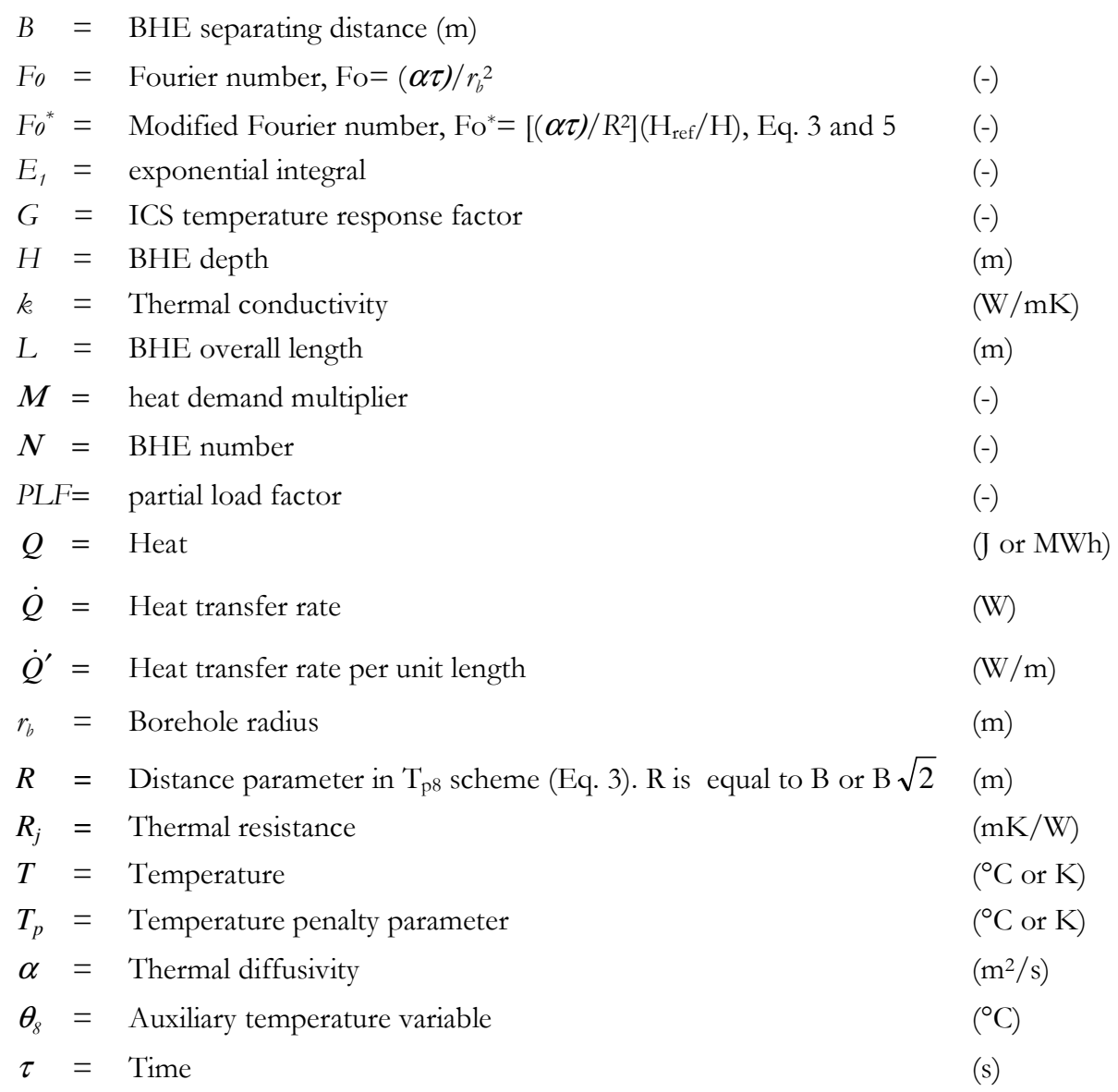

\section{Subscripts}

$\infty \quad=$ undisturbed conditions

$8=\mathrm{T}_{\mathrm{p} 8}$ method

build $=$ at building side

bhe $=$ relative to the $\mathrm{BHE}$

$E E D=$ EED code

fluid, ave $=$ of the carrier fluid, average in and out value 


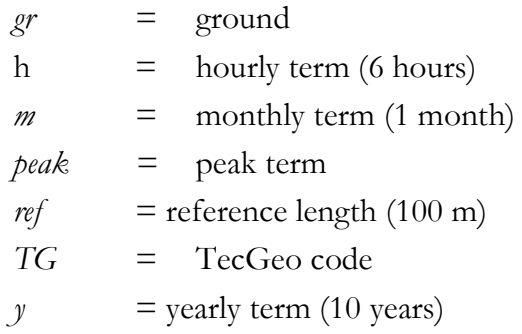

\section{REFERENCES}

Abramovitz, M. and I. Stegun. 1964. Handbook of mathematical functions with formulas, graphs, and mathematical tables. Nat. Bureau of Standards 228-233.

ASHRAE. 2015. Chapter 34, Ashrae Handbook-HV AC Applications: Geothermal Energy Atlanta: ASHRAE.

Bernier, M. 2006. Closed-loop ground-coupled heat pump systems. ASHRAE Journal 48(9):12-19.

Carslaw, H.S. and J.C. Jaeger. 1947. Conduction of Heat in Solids, Claremore Press, Oxford, U.K.

Cimmino, M., M. Bernier and F. Adams. 2013. A contribution towards the determination of g-functions using the finite line source. Appl. Therm. Eng. 51: 1-2.

Claesson, J. and S. Javed. 2011. An analytical method to calculate borehole fluid temperatures for time-scales from minutes to decades. ASHRAE Trans. 117 (2): 279-288.

Cullin, J.R., J.D. Spitler, C. Montagud, F. Ruiz-Calvo, S.J. Rees, S.S. Naicker, P. Konečný and L.E. Southard. 2015. Validation of vertical ground heat exchanger design methodologies, J. Science and Technology for the Built Environment 21(2): 137-149.

Dalla Pietà, D. and M. Fossa. 2006. Modeling and design of borehole heat exchangers for ground-source heat pump applications. XXIV Italian Heat Transfer Conference UIT, Naples 21-23 june 2006.

Eskilson, P. 1987. Thermal analysis of heat extraction boreholes. Ph.D. Thesis, Lund University of Technology, Sweden.

Fossa, M. 2016. Correct design of vertical borehole heat exchanger systems through the improvement of the Ashrae method, Science and Technology for the Built Environment, Accepted for Publication.

Fossa, M. and D. Rolando. 2015. Improving the Ashrae method for vertical geothermal borefield design, Energy and Buildings 93: $315-$ 323.

Fossa, M. and D. Rolando. 2016. Improved Ashrae method for BHE field design at 10 year horizon, Energy and Buildings $116: 114$ 121.

Hellström, G. and B. Sanner. 1994. Earth Energy Designer: software for dimensioning of deep boreholes for heat extraction, Department of Mathematical Physics, Lund University, Sweden.

Ingersoll, L.R., O.J. Zobel and A.C. Ingersoll. 1954. Heat conduction with engineering, geological, and other applications, McGrawHill, New York.

Kavanaugh, S.P. and K. Rafferty. 1997. Ground-source heat pumps: design of geothermal systems for commercial and institutional buildings. ASHRAE, Atlanta, Georgia.

Lamarche, L. and B. Beauchamp. 2007. A new contribution to the finite line-source model for geothermal boreholes, Energy Build. 39 : 188-198.

Priarone, A. and M. Fossa. 2016. Temperature response factors at different boundary conditions for modelling the single borehole beat exchanger, Applied Thermal Engineering 103: 934-944.

Spitler, J.D. 2000. GLHEPRO A design tool for commercial building ground loop heat exchangers, in: Proc. of the Fourth Int. Heat Pump in Cold Climates Conference, Aylmer, Québec.

Yavuzturk, C. and J. D. Spitler. 1999. A short time step response factor model for vertical ground loop heat exchangers. Ashrae Transactions 105: 475-485. 